U.D.C. 331.21: 364.662 (571.12)

keywords: economic poverty, income differentiation, branch-wise and regional wage differentiation, average labor remuneration, minimum wage, subsistence level of working-age population, progressive taxation, targeted extra payments

A. A. Kuklin, A. G. Leontieva

\title{
NATIONAL POLICY IN REFERENCE TO LABOR REMUNERATION AND ITS INFLUENCE ON POVERTY DYNAMICS IN A REGION
}

The paper emphasizes urgent issues regarding labor remuneration, which need to be settled along with adoption of socioeconomic policy aimed at critical reduction in size of the poor population.

The basic integral parameter specifying level and quality of life is cash revenue. The system of income generation was modified in the process of transition to the market economy by the Russian Federation.
It was specified by reduction of labor remuneration share and emergence of new revenue sources (business activity; property including dividends and interest in terms of deposit payouts to individuals; revenue payout in terms of funds and other capital issues). Welfare payments are another revenue source, namely: retirement pensions, financial allowance and social assistance, educational allowance, insurance indemnity and other inpayments. 
Salary is a major factor within the income framework. It takes the following shares in the total income by the population: $65 \%$ in Great Britain, $64 \%$ in Germany, $52 \%$ in Italy, $53 \%$ in the USA, $58 \%$ in France, $69 \%$ in Japan, 35-40\% in Russia (65$68 \%$ if shadow income is taken into consideration). Salary size and regular payouts affect a standard of population well-being and chances for people (particularly with low income) to cover their vital requirements. In addition, salary acts as a source for welfare payments, a regulator of purchasing power by people, a principal motivating tool for labor productivity growth. Salary, being inseparably associated with economic activity by population, has a more considerable influence on economic development in comparison to other income types. High-significance functions that salary bears in the system of economic relationship make it the principal object of regard by government authorities in the context of adopting a socioeconomic policy.

Reduction of salary share in the total revenue from $74,1 \%$ in 1990 to $42,9 \%$ in 2001 is concerned with drastic, almost twofold decline in production (service) volume, reduction of manpower cost (price increase regarding raw materials and fuel had been exceeding salary growth rate), growth of revenue share referred to business activity and property. In addition, a major part of employers had been choosing rather to reduce labor remuneration, than to cut down a number of employees during the economic slowdown.

In 2008 labor remuneration share in the cash revenue structure amounted to $68,6 \%$ [2]. In addition to that it is essential to consider the fact that approximately $30-40 \%$ of the total labor compensation fund is concealed from the statistical inquiry. Hidden income in Russia as a whole is referred to salary, and the given fact makes its share multiplied within the revenue structure. However, hidden income in the regions is referred to the revenue of different kind; therefore the share of the latter is increased, while the labor remuneration share is reduced to $35-40 \%$. Thus, regarding the Tyumen region, labor remuneration related to primary employment took $37-43 \%$ within the revenue structure of the majority of the employed population for the last few years (Table 1).

The years from 1992 to 1998 have been specified by considerable loss in terms of the actual substance of labor remuneration, as it went down in value

Cash revenue structure in the south of the Tyumen region, \% [3, p. 34]

\begin{tabular}{|l|c|c|c|c|c|c|c|c|c|}
\hline \multicolumn{1}{|c|}{ Source of income } & $\mathbf{2 0 0 0}$ & $\mathbf{2 0 0 1}$ & $\mathbf{2 0 0 2}$ & $\mathbf{2 0 0 3}$ & $\mathbf{2 0 0 4}$ & $\mathbf{2 0 0 5}$ & $\mathbf{2 0 0 6}$ & $\mathbf{2 0 0 7}$ & $\mathbf{2 0 0 8}$ \\
\hline Labor remuneration & 37,6 & 41,7 & 43,1 & 37,4 & 41,0 & 37,6 & 37,9 & 40,0 & 38,9 \\
\hline Social assistance & 10,4 & 9,9 & 10,2 & 8,7 & 9,5 & 11,8 & 10,8 & 10,2 & 10,4 \\
\hline Property revenue & 4,0 & 2,8 & 5,7 & 7,2 & 10,5 & 14,4 & 6,9 & 6,8 & 5,9 \\
\hline Business activity revenue & 9,3 & 7,8 & 7,4 & 9,2 & 10,4 & 10,8 & 10,5 & 10,8 & 7,6 \\
\hline Other & 38,7 & 37,8 & 33,6 & 37,5 & 28,6 & 25,4 & 33,9 & 32,2 & 37,2 \\
\hline
\end{tabular}

Table 2

Average monthly posted labor remuneration of employees in the Russian Federation given in the rates referred to 1991 [2]

\begin{tabular}{|c|c|c|c|c|}
\hline \multirow[b]{2}{*}{ Years } & \multicolumn{2}{|c|}{$\begin{array}{c}\text { Monthly labor remuneration in the rates of the } \\
\text { corresponding year }\end{array}$} & \multirow{2}{*}{$\begin{array}{c}\text { Monthly labor } \\
\text { remuneration in the } \\
\text { rates referred to 1991, } \\
\text { rub. }\end{array}$} & \multirow{2}{*}{$\begin{array}{l}\text { Relationship of average monthly } \\
\text { labor remuneration and social } \\
\text { assistance payouts to the } \\
\text { subsistence level of the working- } \\
\text { age population }\end{array}$} \\
\hline & $\begin{array}{l}\text { rub. (since } 2000 \text { given in } \\
\text { the rate scale that is active } \\
\text { since } 01.01 .1998 \text { ) }\end{array}$ & $\begin{array}{l}\text { USD (in terms of annual } \\
\text { average US dollar rate) }\end{array}$ & & \\
\hline 1991 & 548 & $\ldots$ & 548 & 335 \\
\hline 1992 & 5995 & 22 & 369 & 299 \\
\hline 1995 & 472392 & 103 & 246 & 179 \\
\hline 2000 & 2223 & 79 & 238 & 172 \\
\hline 2001 & 3240 & 111 & 286 & 204 \\
\hline 2002 & 4360 & 139 & 332 & 226 \\
\hline 2003 & 5498 & 179 & 368 & 244 \\
\hline 2004 & 6740 & 234 & 407 & 264 \\
\hline 2005 & 8555 & 303 & 459 & 268 \\
\hline 2006 & 10634 & 391 & 520 & 293 \\
\hline 2007 & 13593 & 532 & 610 & 332 \\
\hline 2008 & 17226 & 694 & 677 & 334 \\
\hline
\end{tabular}




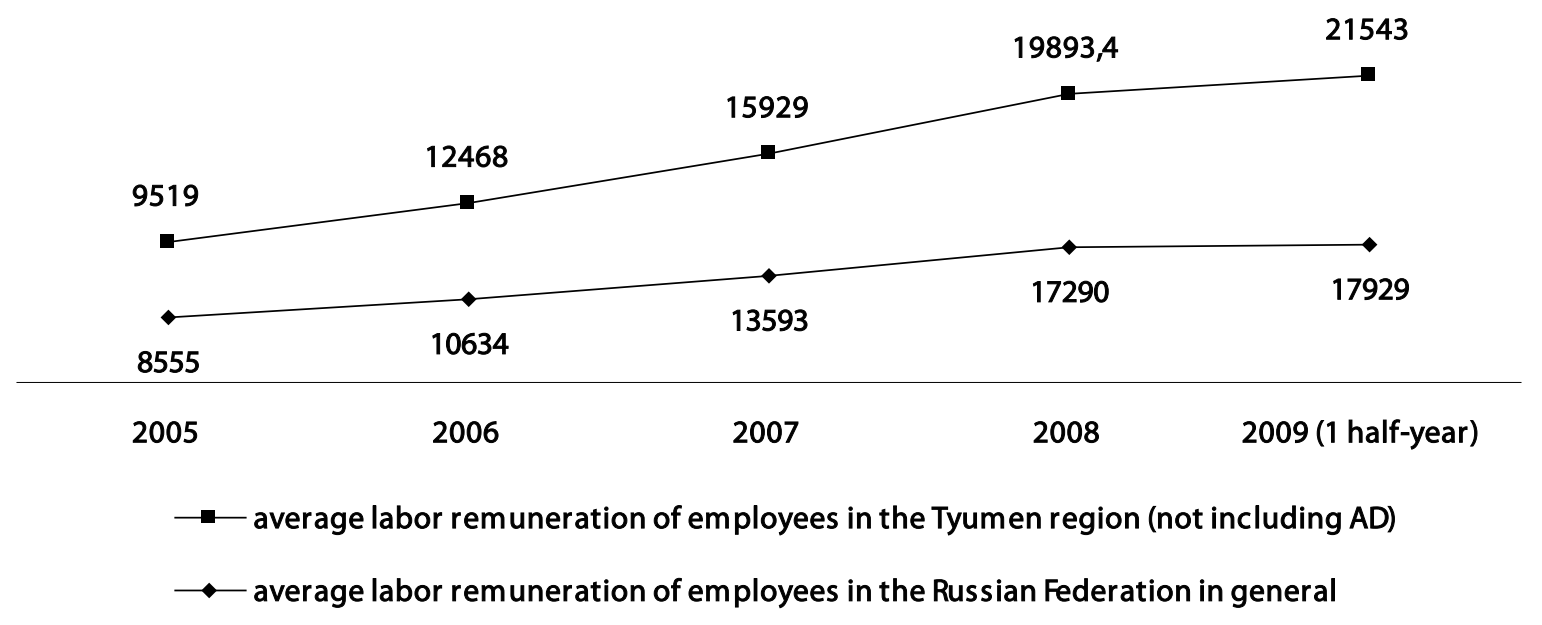

Fig. 1. Dynamics of average labor remuneration growth

almost 2,5 times as much. Rehabilitation referred to labor remuneration growth started in 1999. A pre-reform level of average monthly posted labor remuneration was reached only by 2007 . If the posted labor remuneration is compared to the subsistence level of the working-age population, the given ratio still remains lower than it was by 1991 (Table 2).

Average labor remuneration in nominal calculus has grown 2 times as much during the past five years in Russia, and it reached 17929 rubles in the first half-year of 2009. Along with that, growth rates regarding factual labor remuneration exceeded growth rates of actual revenue by the population. In the Tyumen region (not including the autonomous districts) average monthly nominal posted labor remuneration of one employee at an enterprise (not including small business entities) amounted to 21543 rubles, which is above average by $20,2 \%$ in Russia (Fig. 1). The relationship of average monthly labor remuneration of one employee to cash revenue per capita amounted to $118,6 \%$ and 4,1 times - to the value of the subsistence level of the working-age population.

However, the positive averaged showing conceals grave unsettled issues. In opinion by A. Shevyakov, the director of the Institute for social and economic problems of population, approximately $45 \%$ of labor remuneration total increment was due to labor remuneration growth concerning $10 \%$ of the most highly-paid employees, and over $60 \%$ - due to labor remuneration growth concerning $20 \%$ of employees with the highest salaries. Contribution by the increment in terms of the lowest salaries to the labor remuneration total increment amounted to less than $3 \%[5$, p. 54]. Thus, labor remuneration growth in the country does not give rise to substantial improvement of the condition by low-income population groups. In addition to that, manpower cost in our country is manifold understated in comparison to its actual cost. Thus, if labor remuneration by hour at manufacturing industries of Germany and France is at a level of 30 euro, it hardly goes beyond 2 euro in the Russian Federation, i.e. it is less nearly 15 times as much. Even allowing for the fact that our country lags behind the developed countries in terms of working efficiency two or three times as much, the gap in terms of labor remuneration level is three-five times as much [1, p. 29].

It is well-known that, uppermost, manpower minimum price (minimum wage) increment is required for substantial revenue growth. According to the data by the International Labor Organization, a minimum wage in most countries amounts to $40-$ $60 \%$ of the average labor remuneration and it exceeds a physiological subsistence level several times as much [4]. However, the given ratio is not observed in the Russian Federation. Since 01.01.2009 the minimum wage is set equal to 4330 rubles in Russia. It is $78,8 \%$ of the subsistence level rate regarding working-age population and only $24,8 \%$ of the average wage [2].

Minimum wage in the Tyumen region is fixed by the regional agreement issued by the Government of the Tyumen region, the Tyumen interregional trade union association «The Tyumen regional council of trade unions», the regional association of employers «The Council of employers of the Tyumen region». The minimum wage extent has been fixed at a level 3900 rubles since 1 January 2009. It is 83\% of the subsistence level rate regarding workingage population and $19,6 \%$ of the average labor remuneration in the region.

Gradual increase in the minimum wage to be equal to the subsistence level with the objective to reduce low-income population size is officially planned by the Government. Along with that, in 
opinion by experts, activity aimed at minimum wage increment, though being necessary, will virtually reduce the effect to zero with the course of time in case the existing distribution mechanisms are not modified, as it will result in income growth of, first of all, the wealthiest, not the low-income population groups [5, p. 60]. Therefore, in order to reach the objective of actual reduction of the poverty scale, it is necessary to restructure the existing mechanisms of income distribution, which generate and reproduce social and economic stratification of the society. Fiscal control tools need to be applied to reach the given objective.

Labor remuneration differentiation according to branches, enterprises and employee ranks is a vital issue at present. Thus, labor remuneration analysis within the branch-wise profile for the Tyumen region identified the fact that among the real economy branches the highest labor remuneration level refers to the financial sector $-37,6$ thousand rubles (exceeding the regional level almost 2 times as much), and to the fuel and energy resource production -43 thousand rubles (exceeding 2 times as much). Along with that, the share of employees occupied in the specified scopes of activity is small and it amounts correspondingly to 2,9 and $0,3 \%$ of the general average number of employees. High remuneration is observed among employees occupied in the real estate dealership, leasing and rendering services $-29,9$ thousand rubles. $8,8 \%$ of the general number of employees are occupied in the given sector.

Regarding manufacturing activity, extremely low labor remuneration was established at clothing manufacture (6,1 thousand rubles). The wage level is lower 3,3 times as much than the average in the region. At leather production sector labor remuneration amounts to 9,3 thousand rubles, wage level is $47 \%$ of the average. Agriculture, hunting and forestry are also to be singled out among the economic activities with low labor remuneration. $5,8 \%$ of the general number of the employed are amounted with reference to the given activities, and labor remuneration gap in comparison to the average value is 1,9 times as much. At the fishery and fish-breeding $0,1 \%$ of employees are occupied with the wage 8,3 thousand rubles, which is less 2,5 times as much than the average level [3, p. 29].

Traditional differentiation of labor remuneration among social service workers, who play a fundamental part in human potential development, is still a common practice. Average monthly posted labor remuneration of one employee at a sector of public health and social services (14,5 thousand rub., or $75,4 \%$ of the average in the region) as well as an education sector $(70,5 \%)$ has not reached the average level.

Branch-wise differentiation in terms of labor remuneration inevitably affects territorial differentiation. The difference between the territories of the Tyumen region in terms of labor remuneration per one employee is 3 times as much. According to the labor remuneration level among the municipal entities of the southern areas of the Tyumen region the top position is steadily kept by Tyumen, the administrative center $(25,4$ thousand rub.), and the Uvat area (30,8 thousand rub.), where regional wage coefficient equal to 1,4 is applied, as well as percentage allowance for the record of service in a northern region. The lowest labor remuneration level (less than 11 thousand rub.) is traditionally observed in agricultural territories: the Vikulovo, Kazansky, Ishim, Yalutorovsk areas. High specific weight of people employed in agriculture with low labor remuneration is a distinctive feature of the mentioned areas.

Another type of differentiation in terms of labor remuneration is observed among the people employed in the public, municipal and non-state sectors of economy. In 2008 labor remuneration of every second employee at organizations with nonstate patterns of ownership exceeded the average in the region, while at organizations with state and municipal patterns of ownership that held true only for every eighth employee.

Labor remuneration deflections have a negative impact on the social and economic development of the country. The retained differentiation of employees in terms of labor remuneration level with relatively low average wage is a factor that stipulates poverty retention of the employed population. The given problem is particularly specific of the rural areas and the public sector. The majority of researchers consider the issue of economic poverty abatement to be the first-priority task in terms of the social and economic policy in the regions for the present. Both development of targeted aid programs and arrangement of conditions for earning the means sufficient for self and family sustenance by the economically active group of population will stimulate solution of the given task. For the purpose of economic poverty abatement efforts by the federal and regional authorities are to be consolidated, and a set of measures to influence the labor remuneration level and payout regularity needs to be developed.

In 2008 in the Tyumen region $10,0 \%$ of the population were considered poor, i.e. people with the income below the officially set subsistence level; it is less by $3,7 \%$ than the concurrent showing referred to the Russian Federation in general $(13,7 \%)$. 
Dynamics of the subsistence level rate and the poor population number in the south of the Tyumen region [3]

\begin{tabular}{|l|c|c|c|c|c|c|c|c|c|}
\hline \multicolumn{1}{|c|}{ Index } & $\mathbf{2 0 0 0}$ & $\mathbf{2 0 0 1}$ & $\mathbf{2 0 0 2}$ & $\mathbf{2 0 0 3}$ & $\mathbf{2 0 0 4}$ & $\mathbf{2 0 0 5}$ & $\mathbf{2 0 0 6}$ & $\mathbf{2 0 0 7}$ & $\mathbf{2 0 0 8}$ \\
\hline $\begin{array}{l}\text { Average subsistence level rate (SL) per } \\
\text { capita per month, rub. }\end{array}$ & 942,0 & 1137,0 & 1533,0 & 1814,0 & 2308,0 & 2605,0 & 3293 & 3885,0 & 4519,3 \\
\hline Ratio of a subsistence level rate in times to: & 2,4 & 2,8 & 2,8 & 3,3 & 2,8 & 3,3 & 3,4 & 3,6 & 3,7 \\
\hline \begin{tabular}{l} 
income revenue per capita \\
\hline $\begin{array}{l}\text { monthly average labor remuneration per } \\
\text { one employee }\end{array}$
\end{tabular} 2,3 & 3,0 & 3,0 & 3,1 & 3,0 & 3,3 & 3,6 & 3,9 & 4,0 \\
\hline $\begin{array}{l}\text { population size with cash revenue below } \\
\text { the subsistence level, thousand people }\end{array}$ & 400,5 & 369,7 & 319,2 & 270,8 & 218,0 & 200,7 & 154,0 & 142,2 & 132,1 \\
\hline percentage from the total population size & 29,5 & 27,5 & 24 & 20,5 & 16,5 & 15,3 & 11,7 & 10,8 & 10 \\
\hline
\end{tabular}

Deficiency index of available resources per one household, which specifies poverty profoundness, amounted to 4642,0 rubles in the south of the Tyumen region in 2008; 1347,1 rubles - per one household member [6, p. 13]. The major part of lowincome citizens of the given region lives in a rural area. In 2008 poor households amounted to $59 \%$, and extremely poor households (with an income or available resources less two or more times as much than the subsistence level rate) $-89,2 \%$. A total number of low-income citizens of 132,1 thousand people included the employed citizens amounting to $24,5 \%$ [6, p. 15]. Dynamics of the poor population number is demonstrated in Table 3.

The market mechanism cannot independently overcome the contradiction that occurred in the distribution relationship without interference by the Government. Purposeful regulation of a dynamics level regarding labor remuneration differentiation is required both on the part of the central and regional authorities. At present, new approaches to generation of the state policy in terms of labor and its remuneration are to be developed. An urgent issue is not merely labor remuneration level increment, but also fundamental change of the distribution relationship mechanism itself. Let us specify major tasks, which need to be resolved in the short and medium term.

Uppermost, minimum wage should be first brought to the standard according to the Labor Code of the Russian Federation - specifically, to the subsistence level; then it should reach the European standard of $60 \%$ of average labor remuneration on the basis of improvement of the existing forms and systems of labor remuneration. The given issue, resolvable legislatively at the federal level, will become an incentive for growth in working efficiency by employees, production volume by enterprises and economic efficiency.

The scope of Government control includes also straight regulation of labor remuneration within the public sector. Considering the fact that a considerable part of employees (almost $18 \%$ of the total number of the employed population in the Tyumen region) is occupied in the public sector, labor remuneration increment regarding the given workers can be accomplished by way of additional payments (allowance for continuous record, compensatory allowance etc.) from the regional budget. Enhancement of the branch-wise systems of labor remuneration aimed at convergence of medium wage of public-sector employees with the labor remuneration size established at the extrabudgetary domain, will favor labor remuneration growth. Keeping the balance with average monthly labor remuneration in the real sector of economy is a minimum requisite step to prevent mass outflow of skilled personnel from state-financed organizations and quality depreciation regarding services rendered to the population.

A significant source of labor remuneration increment is establishment of higher share of labor remuneration in a final product. In case if labor remuneration specific weight in production (services) is not substantially enhanced, personal income will be impossible to raise; therefore, if purchasing power by the citizens is not enhanced, economic advance and replenishment of off-budget social funds cannot be accomplished either. In the long term labor cost included in final production is to reach the level of $40-60 \%$ by analogy with countries with developed market economy. One of the suggested ways to solve the given task is to introduce tax discrimination mechanism consisting in higher profit tax payment by enterprises with understated share of labor remuneration in terms of added value or final product cost [4, p. 63].

Another alternative is to intensify an impact on labor remuneration by means of social partnership procedures. It is social partnership that is to determine minimum wage, labor remuneration correlation regarding the most significant occupations, maximum dimensions of differentiation between the employed population categories through the system 
of contracts and rate agreements on the assumption of financial ability by enterprises, branches and the budget of all levels. Agreements have to include liability in terms of labor remuneration increment regarding public sector employees and correlation of the given labor remuneration with that in industry. In addition to that, as far as branch-wise agreements are concerned, it is reasonable to secure the labor compensation fund minimum share in gross receipt from sales of products (services); and in regional agreements labor remuneration level is to be determined on the assumption of characteristics referred to living standard rates in Russian regions. The given mechanism of salary adjustment affords an opportunity to reduce the differentiation level between branches and regions.
It is also possible to smooth excessive labor remuneration differentiation through the system of taxes and payments charged to salary: progressive taxation of high incomes and redistribution of tax revenue for the purpose of low labor remuneration increment. Labor remuneration increment could be stimulated by differential application of the unified social tax (UST), so far as the same UST rate applied for all enterprises and organizations actually puts them in unequal position.

Labor remuneration growth is concerned with task solution regarding «shadow» salary payout to the working population. The given factor reaches $25 \%$ in the Tyumen region. Steps by the Regional interagency committee for labor remuneration issues jointly with the Administration of the Federal Tax

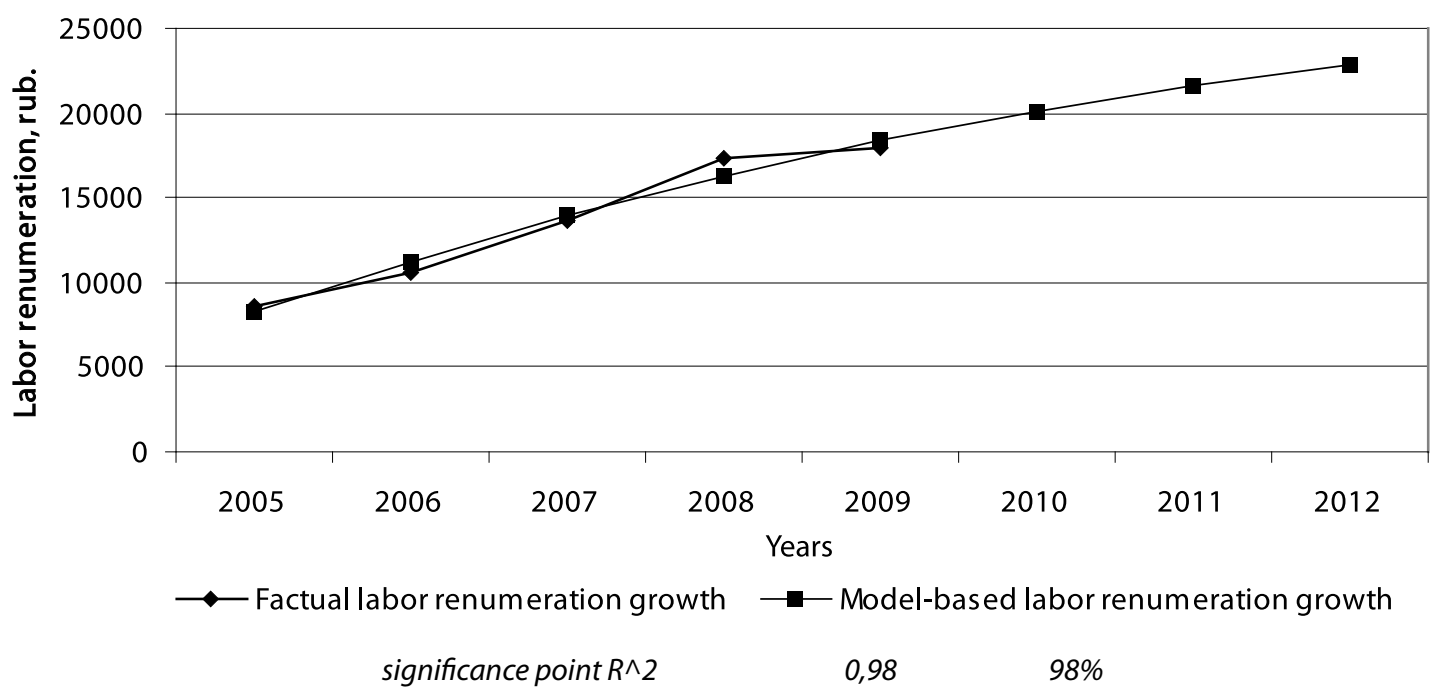

Fig. 2. Dynamics of labor remuneration growth in the Russian Federation with reference to the forecast for 2010-2012

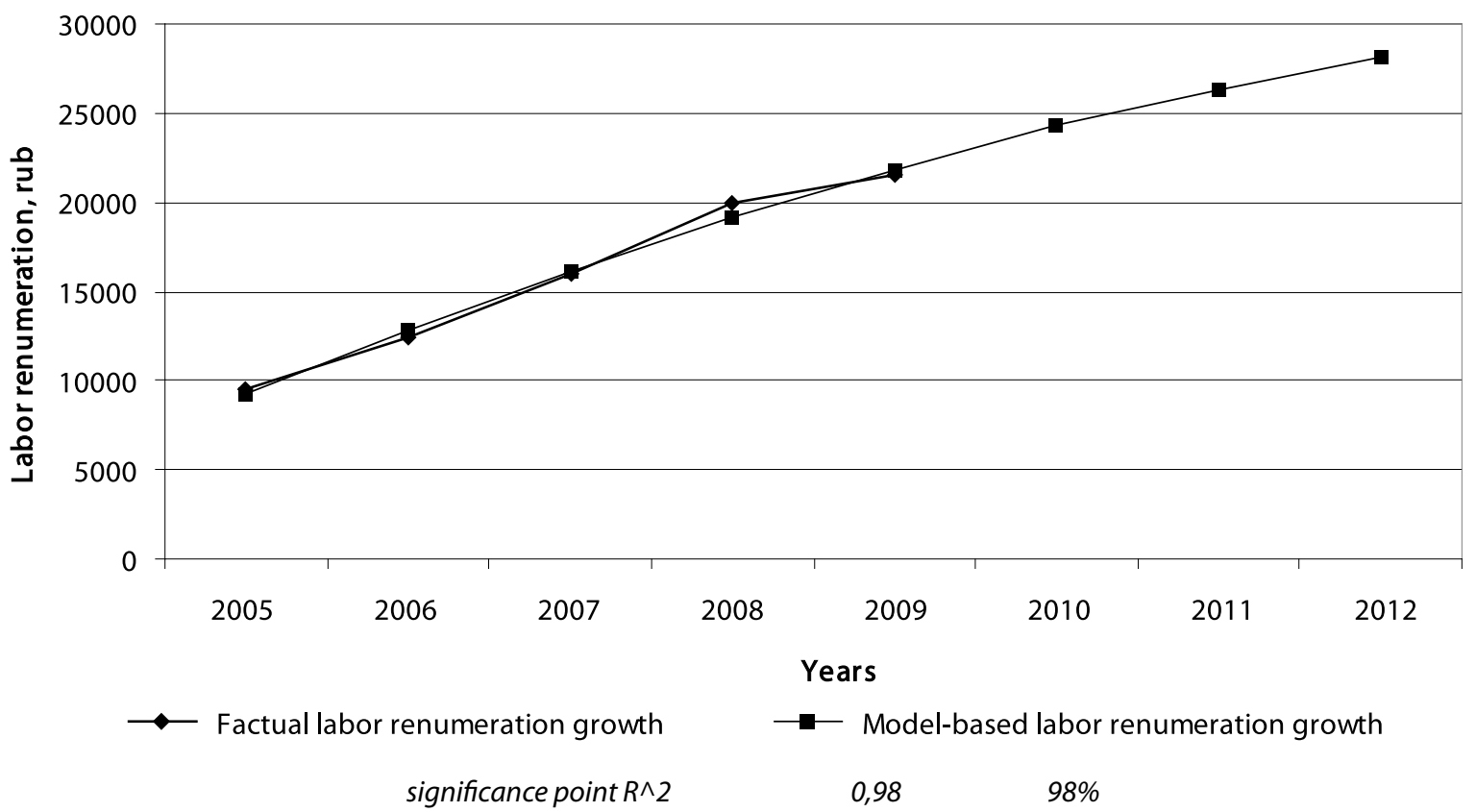

Fig. 3. Dynamics of labor remuneration growth in the south of the Tyumen region with reference to the forecast for 2010-2012 
Factual and predicted average labor remuneration growth

\begin{tabular}{|l|c|c|c|c|c|c|c|c|}
\hline \multicolumn{1}{|c|}{ Rate } & $\mathbf{2 0 0 5}$ & $\mathbf{2 0 0 6}$ & $\mathbf{2 0 0 7}$ & $\mathbf{2 0 0 8}$ & $\mathbf{2 0 0 9}$ & $\mathbf{2 0 1 0}^{*}$ & $\mathbf{2 0 1 1}^{\star}$ & $\mathbf{2 0 1 2}^{\star}$ \\
\hline $\begin{array}{l}\text { Average monthly labor remuneration } \\
\text { in the Russian Federation, rub. }\end{array}$ & 8555 & 10634 & 13593 & 17290 & 18375 & 20150,4 & 21619,8 & 22783,2 \\
\hline $\begin{array}{l}\text { Average monthly labor remuneration } \\
\text { in the Tyumen region, rub. }\end{array}$ & 9519 & 12468 & 15929 & 19893,4 & 21866 & 24265,01 & 26364,67 & 28164,99 \\
\hline
\end{tabular}

forecast data

Service of the Russian Federation in the Tyumen region made it possible (during only 2007) to reduce by $1,5 \%$ the number of workers with salary below the subsistence level in the total number of employed citizens of the Tyumen region [3, p. 207]. Therefore, it is essential to intensify efforts at the local level in terms of detection and penalty of employers, who pay salary in pay-packets.

Based on the standard model of straight-line regression, we made forecast calculations referred to labor remuneration increment for next few years with retention of the existing social and economic dynamics (Fig. 2, 3).

Coefficient of determination $\mathrm{R}^{2}$ equal to 0,98 demonstrates high degree of accuracy under return dynamics approximation; respectively, it specifies sufficient extent of relevance of the regression model. Data regarding factual and calculated value of labor remuneration are shown in Table 4.

However, in order that labor remuneration growth was attended by reduction of poor population number, subsistence level dynamics should be taken into consideration. So far as a subsistence level rate is determined and approved regionally, it depends on regional budget potential and, consequently, it is rather subjective. Subsistence level increment gives rise to general poverty level increment, so long as a poor population group inevitably comprises poverty-prone individuals, i.e. people with income insignificantly above the poverty line. Therefore, it is essential to maintain subsistence level growth rates to be adjusted to labor remuneration growth rates and poor population estimated strength, which is a key point for local social and economic policy.

Labor remuneration growth forecast in the Tyumen region based on the existing correlation of the wages and subsistence level of the workingage population makes it possible to assume that retention of the current social and economic trends requires, under otherwise equal conditions, that subsistence level growth rate for the next few years is maintained at $10,1 \%$ on the average. Workingage population subsistence level rate will be equal to 6869,5 rub. in 2012 . Therewith, the regional poverty line will not exceed a critical threshold in order that social stability was retained. Though, the matter in this case is concerns only total poverty stabilization. Reduction of the objective poverty is to be attained by substantial (approximately 2 times as much) increment of the subsistence level by way of renewal of the market basket both in the federal center and in regions.

Thus, state policy regarding labor remuneration is to be aimed at stimulation of manpower cost increment and labor remuneration growth subject to production volume growth and consolidation of financial status of enterprises in regions. In addition, it is essential to take measures with an objective to prevent illegal labor remuneration payout and secure total record of paid salary. The given measures are associated with solution of the task concerned with reduction of the level, scale and profoundness of poverty only in case if distribution mechanisms are adjusted in the direction of balancing of financial condition in reference to various income groups.

\section{References}

1. Roik $V$. To the issue of generation of modern pension insurance establishment in the country // Russian economic journal. 2009. №1-2. p. 26-33.

2. Russia in figures. 2009 // Federal State Statistics Service. [on-line resource]. URL: www.gks.ru

3. The Tyumen region in figures: brief statistics collective paper in 4 parts. Part 4. / Regional authority under the Federal State Statistics Service in the Tyumen region. Tyumen, 2009. $226 \mathrm{p}$.

4. Chekanov E. Minimum wage adjustment: international regulations and national peculiarities // Man and labor. 2006. №8. p. 61-64.

5. Shevyakov A. Social policy impact on condition of individual population groups // Economist. 2008. № 9. p. 54-84.

6. Living standard in the Tyumen region (2004-2008): statistics collective paper in 2 parts. Part 1. / Regional authority under the Federal State Statistics Service in the Tyumen region. Tyumen, 2009. 351 p. 